\title{
Fazeres ordinários da cla s s e: uma aposta para a pesquisa e para a formação ${ }^{1}$
}

Anne-Marie Chartier

InstitutNationaldeRecherchePedagogique

Não é fácil falarda práti ca de ou traforma senão de maneira negativa.

Pierre Bourdieu

Ao subir, descer, girar ao redor das práticas, al guma coisa escapa sem cessar, que não pode ser dita nem ensinada, mas deve ser praticada.

Michel de Certeau

Por meio de trabalhos sobre a escola, oriundos dos campos de pesquisa mais diversos, po de-selevan tarum in ven tá rio de apro ximações existentes. Desenham-se a partir disso três formas principais de discursividade. A primeira reúne as pesquisas inscritas no campo das Ciências Sociais. Elas são identificáveis por sua inscrição disciplinar: História, Sociologia, Etnologia, Economia, Psicologia, Lingüística. A segunda se define menos por seus métodos e suas referências que pelos fenômenos por meio dos quais ela se dá como objeto de estudo. Nesta se concentram as pesquisas em Didática (o saber ensinado, vinculado às normas federais) e aquelasquesão con cernentes às problemáticas nascidas nas instituições escolares (pro cessosdetransmissão, deavaliação, de inovação, de formação etc.). Ao lado desses estudos formam-se corpos de conhecimento legítimos, como também reservatórios de modelos de análise existentes de outros discursos que acompanham e nutrem as práticas. Este terceiro estrato, que representa a performance, marca os diferentes poderes que se exprimem nos espaços públicos: governo, administração, sindicatos, associações profissionais ou de utilitários, grande imprensa e imprensa especializada, edição escolar etc. Os programas, as circulares, os textos oficiais, como também os manuais, os livros do mestre ou, hoje, os didáticos e os referenciais constituem o pólo prescritivo. Os discursos críticos (uma outra forma de performance) formam um segundo pólo, os quais dizem respeito às transformações do sistema educativo e às decisões que os acompanham. São, em geral, conflituais e fortemente mediatizados. Freqüentemente polêmicos e ideológicos, não são necessariamente políticos e podemcoabitar com os tex tosdo pólo precedente: numa revista profissional, um artigo mais técnico na forma (proposições didáticas, análise crítica de um funcionamento pedagógico etc.) pode ser, indiretamente, uma cargaviolenta contraaescola tal como ela é.

Esse é um ponto comum a todos os tipos de discurso. Eles supõem conhecido 0 que existe e perdura, apoiando-se no fato de que se dirigem aos atores da escola ou ao grande público, eles têm sempre à sua frente interlocutores informados. Os primeiros são, com efeito, pensados, porque praticantes, como os experts do sistema escolar; e os segundos, porque pertencentes a uma sociedade fortemente escolarizada, estão do tados de um saber empírico sobre a escola tal como ela é, o que não seria negado nem a um

1. Do original: Les 'faires' ordinaires de la classe: un enjeu pour la recherche et pour la formation. Millieu et liens sociaux. Yves Grofmeyer (Ed.) Programme Pluriannuel de Recherche en Sciences Humaines, Rhôn-Alpes, 1993. Tradução de Diana Gonçalves Vidal, Valdeniza Maria da Barra e Vera Lúcia Gaspar da Silva. A edição manteve o sistema de referência em notas de rodapé utilizado pela autora. 
antigo aluno, nem a um pai de aluno. Assim, os trabalhos científicos, os textos e as ferramentas profissionais, os debates de idéias em torno dasapostaspresen tes ou dasmissõesfuturas da escola são dos gêneros discursivos que somente tomam sentido se relacionados a uma realidade escolar supostamente conhecida, designada sem cessar mas não descrita, a não ser de maneira incidental ou indireta. 0 que é invocado, mas ausente, é o que se faz na escola, o que se faz hoje ou o que é sem prefeito, enfim, a prática escolar.

Ora os fazeres ordinários são variáveis ignoradas ou não controladas na maior parte das si tu a ções de pesqui sa. São, por ou tro lado, elementos essenciais à transmissão do saber-fazer profissional, apesar de colocados no lugar de uma formação institucionalizada e escolarizada que produz sempre sua desqualificação ou sua negligência. ${ }^{2}$ Dois tipos de pesquisa podem colocar de maneira flagrante 0 fenômeno em evidência: as pesquisas históricas e as comparações internacionais. Num ou noutro caso, o pesquisador que constrói sua interpretação de fon tes a par tir de seu tem po e de seu lugar (por exemplo, a última década do século XX na França) arrisca-se incessantemente em cair em uma cilada por causa delas. Os saberes implícitos que ele constitui empiricamente em um ambiente são às vezes destinados a serem ineficazes (ele não compreende a que fazem alusão os textos, a quais realidades escolares supõem), às vezes já induzidos a assimilações (ele marca sobre uma realidade escolar passada ou distante os esquemas postos numa experiência escolar próxima, multiplicando os contra-sensos). É portanto desejável, para se construir rigorosamente o objeto, fazer emergir o que o discurso supõe conhecido sem o dizer. Pode-se tomar, como exemplo, duas pesquisas recentes, que põem em evidência a necessidade e a dificuldade de uma investigação dos gestos escolares da aprendizagem quando se quer interpretar 0 que se diz sobre a leitura.
As ambigüidades e as dificuldades de uma análise das práticas de escolarização

A pesquisa histórica é permanentemente confrontada aos materiais escolares dos quais a regra de uso não pode ser deduzida, nem induzida a partir das práticas escolares contemporâneas. ${ }^{3}$ Veja- se 0 exemplo das práticas de leitura da escola primária do fim do século XIX: uma aproximação superficial permitiriaacreditar que as concepçõespedagógicas que têm curso nessa época, nesta área, fossem marcadas pelo viés do arcaísmo mais obtuso, somente favorecendo os exercícios mais repetitivos. Entre outras proposições, por exemplo, pede-se freqüentemente, nas revistas pedagógicas, que cada criança leia seus textos até que os saiba perfeitamente. Uma pesquisa sobre os manuais escolares dos anos 1880-1914 ${ }^{4}$ indicou que o livro de leitura utilizado nas classes, entre o Segundo Império e a Terceira República, foi durante muito tempo o único livro escolar e abrangia, portanto, todos os saberes que deveriam ser adquiridos. Se os textos reunidos no livro de lei tu rasão li ções eseapa la vra leituradesigna os momentos da classe nos quais todos liam juntos os textos de Ciência, de História, de Geografia ou de Moral, então se constituía praticamente, para mestres e alunos, uma

2. Em relação aos primeiros trabalhos sobre a evidência da nova formação de professores nos institutos universitários de formação de mestres (IUFM), podem ser consultadas, sobre a reforma de 1969 (que atingiria apenas os professores do primeiro grau), as investigações realizadas por J ean Hébrard, J acqueline Mariet e Frank Marchand nas escolas normais dos anos 1970: ver "Études de Linguistique Appliquée", 32, 1978 e 39-40, 1980.

3. André Chervel, "L'Historie des disciplines scolaires: réflexions sur un domaine de recherche", Histoire de l'education, 38, 1988, pp. 50-119. (Publicado em português: André Chervel, História das disciplinas escolares: reflexões sobre um campo de pesquisa. Teoria \& Educação (2): 177-229, 1990.)

4. Anne-Marie Chartier et J ean Hébrard, Discours sur la lecture (1880-1980). Paris: Centre Georges Pompidou, 1989, pp. 267-306. (Publicado em português: Anne-Marie Chartier e Jean Hébrard. Discursos sobre a Leitura. São Paulo: Ática, 1995.) 
equivalência entre ler e aprender, entre ler e memorizar. A popularização entre os ensinantes das novas práticas escolares (como a lição de coisas na qual se aprende observando e manipulando, e não mais somente lendo) e de um novo material escolar (os livros especializados de Ciências, de História, de Geografia) rompe essa conjunção. Quando o livro de leitura não é mais o livro de todas as lições e quando podem existir as lições sem livro, toda a paisagem pedagógica é perturbada. É necessário que, na linguagem pedagógica, a palavra leitura constitua um novo referente pragmático. Certamente, na boca dos mestres e sob a pena dos pedagogos e das autoridades, a leitura permanece o exercício escolar cujo lugar é o livro de leitura; mas deste livro desaparecem os textos sobre Vercingetórix, sobre a colheita do lúpulo e sobre a circulação da água. Continua-seportanto a fazer as leituras instrutivas em conjunto, mas sobre outros suportes especiais; e, quando se solicita às crianças que peguem seu livro de histórias, ninguém vê ou diz que se fará leitura. 0 que resta então do livro, assim progressivamente diminuído dos conteúdos científicos? Os textos para fazer a educação moral e cultural das crianças, as fábulas de La Fontaine e Pauvres Gens, de Victor Hugo. As finalidades da leitura escolar são assim redefinidas a partir do corpus de escritos que lhe ser ve de suporte específico (pedaçosescolhidos de grandes au to resjulgados acessí veisàscrian ças) e das práticas sociais legítimas que a escola deve promover (a leitura em voz alta diante do público, essa leitura expressiva que exige que se articule e "coloque o tom").

Poder-se-ia assim, ao acompanhar a evo Iu ção dosli vros delei tu ra, acre di tar quea lei tura instrutiva desapareceu um dia das práticas escolares em proveito das leituras literárias. Ora, não é o caso. Tal desaparecimento discursivo provém, de fato, da remodelagem das representações que cada um faz da escola, a partir do momento em que o Francês se torna uma disciplina específica do Ensino Elementar.
Durante mais de meio século ef etuou-se uma nova partilha entre as práticas de leitura com asqua is se fala e debate, aquelas para as quais ler é objeto mesmo do exercício (trata-sedessa leitura expressiva oralizada, mas também da leitura das primeiras aprendizagens) e as que perduram tacitamente uma vez que a leitura é utilizada para outro fim (leituras funcionais e documentais). Para fazer ressurgir as práticas ordinárias, não se pode mais, infelizmente, interrogar os mestres. ${ }^{5}$ Nada impede, no entanto, de fazê-lo para as práticas contemporâneas. Seria mais fácil?

0 segundo exemplo que mencionamos trata, justamente, desta outra parte da leitura, que diz respeito às primeiras aprendizagens. As pesquisas e polêmicas sobre o objeto são excessivamente numerosas para que alguém, mesmo dedicando-se a isso, possahoje lê-las todas. Cada pesquisador deve, portanto, se especializar, estudando um aspecto somente das múltiplas facetas por meio das quais ele pode ver como se constroem os procedimentos de ingresso na escrita. Procurando estimar 0 efeito de variáveis internas no seu campo de estudo, deve integrar neutralizando tanto quanto possível as variáveis envolvidas. Portanto, uma criança não aprende talvez a ler da mesma maneira em inglês ou em chinês (o sistema de escrita não é o mesmo), em in glês, em es pa nhol e em ára be (o sistema de correspondência fonema-grafema não é o mesmo), na Fran ça ou Ca ma rão (a lín gua materna não é a mesma), na Espanha ou

5. Esta dificuldade em reconstruir os referentes pragmáticos desaparecidos conduz, freqüentemente, os pesquisadores a se limitarem a uma aproximação discursiva do fenômeno que estudam e a crer que eles, os fenômenos, são todos atingidos pelas mesmas práticas de uso. Na maioria dos casos, os pesquisadores interpretam seus materiais à luz apenas das práticas contemporâneas, colocando-Ihes questões que não têm sentido retrospectivamente. É 0 caso, por exemplo, de uma tese recente (Christiane ) uaneda-Albarède, L'Enfant et l'apprendissage de la lecture en France, au XIXe siècle. Lecture et compréhension. Université Paris V, Paris, 1990), excelente na sua análise dos discursos didáticos mas freqüentemente imprudente nas suas interpretações. 
México (a obrigação escolar não é a mesma), sobre Guizot, Ferry ou J ean Zay (a taxa de alfabetização dos pais não é a mesma). E mesmo nos países cujos sistemas podem parecer mais próximos (como os países franco-fônicos desenvolvidos: Québec, Bélgica, França, Suíça francesa) pode-se dizer que se conhece o modo pelo qual as crianças aprendem a ler? Pode-se, por exemplo, designar claramente as práticas pedagógicas que apontam de maneira contrastada as expressões como método silábico ou método global? ${ }^{6} \mathrm{Na}$ ocorrência, encontram-se os mais numerosos discursos de método, mas frágeis descrições do fazer ordinário por meio do qual os pedago goscon du zemascrian çasem suas primeiras aprendizagens. Trata-se com efeito deumaatividadeex tremamen tecomple$x a$, freqüentemente eclética e mais preocupada em conduzir a resultados do que compreender como têm sido obtidos. Todas as vezes que um procedimento dá (socialmente) satisfação, ele permanece silencioso; em contrapartida, quando fracassa ao produzir efeito antecipado, os discursos proliferam em torno de tentativas para encontrar as causas do fracasso e realçar desafios. Eis porque "é difícil falardaprática de outra forma senão de maneira negativa", como diz Pierre Bourdieu. ' Fala-se dela porque ela fracassa e apenas interessamo-nos pelo que nela falta. Teoriza-se seu propósito apenas "porque alguma coisa escapa sem cessar, que não pode ser dita nem ensinada mas deve ser praticada", como escreve Michel de Certeau. ${ }^{8}$

A redução da aproximação científica aos objetos de estudo muito bem delimitados, desejável para produzir saberes parciais, mas ob jetivos e capitalizáveis, coloca assim, desde que se trata de estudar as práticas, redobrados problemasdeméto do. Com efei to, numcampo dado, as práticas fazem sistemas e são as convergências práticas, reguladas empiricamente na ação mais que pensadas e decididas, que fazem sua eficácia e comodidade. Ao isolar uma variável, ao definir a priori um objeto, corre-se sempre o risco de perder aquilo que faz seu valor de uso: sua posição relativa aos outros elementos do campo. Por exemplo, investigar o que as crianças lêem nas bibliotecas escolares (uma BCD) e como elas lêem, não tem sentido (prático) se não olharmos que lugar ocupa a biblioteca-centro-documental no conjunto dos dispositivos de leitura de uma classe ou de uma escola. ${ }^{9}$ Para estudar um objeto escolar, somos então conduzidos quase infalivelmente a situá-lo numa estratégia de ensino. Qual crédito, por exemplo, se daria aos resultados de uma pesquisa que, depois de muitas e bem acabadas observações de sessões consagradas à apren dizagem da leitura, em duas partes da classe com métodos diferentes, concluísse pela eficácia superior de um método sobre outro, sem ter levado em conta, nas suas observações, as sessõ es consagradas à ap rendizagem da escrita? ${ }^{10}$ Pode-se decidir que 0 modo de as crianças aprenderem a escrever é sem efeito sobre o progresso na recepção do escrito? E pode-se ignorar os efeitos das práticas de leitura sistematicamente conduzidas fora do tempo atribuído às lições de leitura? Mas, então, é necessário tudo observar, o que está justamente fora de questão. Parece que se chegou diante de uma aporia, já que o tratamento científico das práticas escolares apareceao mesmo tem po necessá rio eirrealizável rigorosamente.

6. Anne-Marie Chartier e J éan Hébrard, "Méthode syllabique et méthode globale: quelques clarifications historiques", Le Français aujourd'hui, 90, juin 1990. pp. 100-109.

7. Pierre Bourdieu, Le sens pratique. Paris: Ed. Minuit, 1980: 135.

8. Michel de Certeau, L'invention du quotidien. Arts de faire. Paris, U.G.E., 10/18, 1980, p. 149. (Publicado em português: Michel de Certeau, A invenção do cotidiano: artes de fazer. Petrópolis: Vozes, 1994.)

9. Ver, por exemplo, Catherine Tourette, "L'intérêt pour la lecture chez les enfants de 6 à 12 ans", Bulletin de psycologie, 35, 355, 1982, pp. $415-425$ et 36, 361, 16-17, pp. 747-756 ou ainda: Françoise Sublet e Yves Prêteur, "Les conduites réflexives d'enfants de 5 à 6 ans vis à vis des livres de jeunesse", Revue française de pédagogie, 85, 1988, pp. 47-54.

10. É o caso de certo número de trabalhos comparativos sobre diferentes métodos de leitura nos anos 1970. 
Somos conduzidos a usar de aproximações conjugando as entradas múltiplas e diversos procedimentos de investigação, indo da monografia local de tipo etnológico à pesquisa pesada, recorren do àsanálisesfatoriais. É nesta segunda direção que está engajada uma pesquisa internacional centrada sobre as práticas de cursos preparatórios ou de primeiro ano primário nos países franco-fônicos. ${ }^{11}$ Os problemasmeto dológicos solucionados para constituir o corpus dos dados têm sido tão instrutivos quanto os primeiros resultados da pesquisa. Assim, vem sendo impossível recorrer a observadores externos para anotar o visível a partir de sua inserção no interior das classes. Aquilo que constitui as práticas como práticas pedagógicas não é racionalmente observável por um terceiro: as preparações feitas fora da classe, as decisões concernentes ao ritmo duran teumano esco lareà di nâ mi ca evo lu ti va das atividades no curso de um ano (modalidade e conteúdo dos exercícios) em função da aquisição da classe; os critérios destinados a orientar asin ter ven ções so breo cam po na di re ção detal ou tal aluno; a maneira de encadear as sessões e de fazer funcionar nas situações de ação, de fala, a convocação explícita ou tácita de outras situações de fala e de ação; tudo isso são táticas praticadas, nas quais as lógicas são colocadas nas temporalidades múltiplas (lógica da urgência imediata, lógica da capitalização na memória e do recordado, lógica das antecipações do programa) que não são imediatamente manifestadas nos comportamentos.

0 questionário elaborado a partir de uma pré-pesquisa (que comporta mais de 450 itens) foi respondido rapidamente, na Suíça e em Québec, por mestres voluntários (o que enviesa evidentemente a amostra). Ele comporta as deman das, tan to so breosaspectosmaismateria is do trabalho (utilização de manuais, de apostilas, de etiquetas, de cartazes etc.), a organização do tempo (número de horas consagradas por dia, por semana, a esta ou aquela atividade), quanto sobre as posições profissionais, as constatações e opiniões em matéria deapren dizagem (opiniões sobre as reformas pedagógicas em curso, opiniões sobre as origens das dificuldades de aprendizagem). Trata-se, portanto, de opiniões e práticas declaradas. Diante da abundância e do ecletismo dos dados recolhidos, somente uma análise fatorial podeestabelecer os perfis de resposta e destacar os estilos didáticos. Assim, apesar de os modelos teóricos dominantes serem os mesmos nos dois países, as práticas pedagógicas são muito mais heterogêneas em Québec que na Suíça. Uma variável essencial nos dois países (a maior ou menor experiência do professor) produz as práticas acentuando as particularidades nacionais (quanto mais os mestres têm experiência, mais usam atividades coletivas, na Suíça; e atividades de leitura au tônoma, em Qu ébec). 0 queestes des vi osproduzem? Que consciência têm os professores da própria maneira de agirem? Sobre quais pontos colocam espontaneamente sua vigilância? 0 que, ao contrário, escapa aos seus próprios olhos?

Uma tal pesquisa permite também colocar em dia as regularidades sintomáticas. Assim, quando um aluno se engana na leitura de uma palavra, um número bem limitado de condutas é possível. Ou o mestre dá a palavra à criança (retificando ele mesmo ou fazendo retificar por uma outra criança); ou ele pede à crian ça para cor ri gir. Nestecaso, osmestres se repartem em duas grandes famílias: ou eles intervêm dizendo à criança "olhe bem o que está escrito" (remetendo assim a um trabalho deidentificação diretaouin diretadapalavra), ou dizem "escute bem o que você falou" (remetendo então à coerência semântica da frase). As diferentes atitudes, longe de ser função do tipo de erro ou do tipo de texto, da

11. J acques Weiss, Enquête internationale sur la lecture en premiére année primaire. Rapport Suisse, IRDP, Neuchatêl, 1988. J acques Weiss, Nicole Grunderbeeck, Gilles Gagné, Unité et diversité de l'enseignement de la lecture en première année primaire au Québec et en Suisse, IRDP, Neuchâtel, 1989. 
época do ano ou das crianças, constituem-se, em verdade, um gesto prático sem conhecimento, que permite, freqüentemente melhor do que o discurso, caracterizar as escolhas didáticas praticadas pelo mestre, identificar em qual metodologia ele se inscreve.

Os dois exemplos, extraídos de pesquisas recentes, mostram o ponto no qual as práticas ordinárias de um sistema escolar, num momento dado, permanecem decididamente enigmáticas, ou melhor impensadas; tão menos pensadas quanto as banalidades das reiterações práticas, consideradas como insignificantes, corriqueiras. 0 equipamento escolar faz assim parte das invisíveis pressões do sistema (o fato de ter escassez ou abundância de livros, de papel e de lápis), assim como tudo que constitui as condições materiais do exercício do ofício. Pode ser necessário refletir, nessa perspectiva, sobre as reivindicaçõessindicais tradicionais, nas quais os professores se colocam sempre sob os ef eitos e os meios. Quando se passa de classes que com por tam mais de 40 alu nos a gru pos de 25 crianças, quais são as novas práticas pedagógicas que se colocam imediatamente e que vão rapidamente fazer perceber esse efetivo, de novo, como muito pesado? A relação mestre-classe está modificada (mas como?), os procedimentos de trabalho - ou de não-trabalho - da criança (inobserváveis no grupo maior) tornam-se visíveis aos olhos do professor, as normas de eficácia, as expectativas, a pressão exercida sobre 0 aluno se modificam na mesma proporção da ignorância daquele que dá aula. ${ }^{12}$

A partir desses exemplos, nós desejamos pontuar um certo número de problemas e, em particular, certas contradições sentidas progressivamente como irredutíveis, entre pesqui sa efor ma ção de um lado, en trefor mação inicial e formação contínua de outro. Pode ser que exista aqui a definição de escoIhas em matéria de políticas educacionais e de formação.
Pesquisa e formação diante da prática: descontinuidades e divergências

Afirma-se, geralmente, como deve vir a ser a complementaridade en trepesqui sa eformação: a pesquisa em educação informaria e questionaria as atitudes formativasgraças aos saberes elaborados em situações experimentais, ou elucidaria as dinâmicas das obras em pesquisa-ação; as práticas formativas permitiriam a difusão de inovações e assegurariam a integração de novos procedimentos didáticos ou pedagógicos na realidade cotidiana das classes, ao preço de reorganizações inevitáveis, mas menores. Essa interaçãoentrepesquisa e formação é, mais do que nunca, atual com relação às Instituições Universitárias de Formação de Mestres (IUFM). Instalar a formação de todos os professores nas universidades é dar uma chance histórica de reaproximar os lugares onde se elaboram os saberes e as pessoas en car rega das desuautilização e de sua difusão, os professores.

Para dar credibilidade a esse projeto, é preciso, portanto, se guardar das reduções simplistas ou das intenções ingenuamente eufóricas. Porque é justamenteessatro caharmoniosa que a experiência contradiz maciçamente. Nos lugares onde a ligação entre formação e pesquisa é antiga (USA, Canadá, Suíça, Bélgica, pois estas universidades estão,

12. Os trabalhos de Allain Mingat colocam problemas desse tipo. Quando ele anuncia, por exemplo, que a variável efetivos somente influencia marginalmente os resultados escolares, enquanto a equação pessoal do mestre, ao contrário, representa um papel capital, ele não fornece os meios para se examinar em que medida a percepção pelo mestre da evolução dos efetivos de sua classe (melhoria subjetiva ou, ao contrário, degradação subjetiva de sua atividade profissional) contribui precisamente para a construção desta equação pessoal (ver Alain Mingat, "Les acquisitions scolaires au CP: les origines des différences?" Revue française de pédagogie, 69, 1984, pp.49-63). Retomam a discussão, alguns anos mais tarde, Marie Duru-Bellat e Christiane Leoy-Audoin ("Les pratiques pédagogiques au CP. Structure et incidence sur les acquisitions des élèves", Revue française de pédagogie, 93, 1990, pp. 5-16), chegando a conclusões mais comedidas e mais prudentes. 
há muito tempo, enraizadas na formação dos professores), tudo se passa como se os procedimentos e os saberes elaborados nas situações experimentais ou controladas (onde os resultados têm sido satisfatórios e devidamente avaliados) fracassassem regularmente ao se difundir. ${ }^{13}$ Os exem plos que se po dem ser da dos no caso francês não contradizem as afirmações gerais. Ora os professores resistem ou parecem indiferentes às proposições saídas da pesquisa, ora, quan do asad mi tem, não ésenão à cus ta de deformações ou atenuações que, aos olhos dos pesquisadores, transformam profundamente 0 sentido e mesmo as finalidades.

A experiência parece mostrar que dois públicos contrastantes coexistem nos estágios de formação contínua. Um, minoritário, está disponível a to dasasaven tu raspedagó gi casea inovação é o centro de sua trajetória profissional; para esses professores familiarizados com os es tá gi oso u comasuni ver si da des deverão, 0 conteúdo hipotético ou científico das informações fornecidas é, por vezes, menos importante que o espaço de reflexão queéassimaber to; ea garantia de pesquisadores é sempre boa porque, hoje, é desejável inovar no en sino. 0 outro público, largamente majoritário, não encontra quase nenhuma resposta às suas questões nos resultados de pesquisas. Os pesquisadores-formadores e os militantes pedagógicosestão sempre prontos a acusar a rotina que sobrecarregaria congenitamente a maioria de seus colegas. Mas a oposição entre prática tradicional e prática inovadora parece recobrir uma análise de fato simplista: os professores recusam a inovação seja por convicção ideológica (de acordo com a conjuntura, esta convicção íntima será amortecida ou aclamada), seja pela preguiça profissional (acredita-se no ganho de eficácia, mas não se deseja fazer o investimento de energia que permitiria obtê-la). Essa concepção voluntarista da prática dá uma imagem extremamente empobrecida da vida profissional, mas favo rável, umavez quecoloca o professor em uma situação de domínio total narelação queestabelece(jul ga, escolhe, quer ou não quer etc.).

Os obstáculos que se encontram na formação contínua e que levariam à rigidez adquirida no exercício do ofício, aprendidos ou não nas tarefas, podem eles servir para uma melhor formação inicial? É um pouco a aposta que fazem os IUFM para os futuros professores do Ensino Médio. Igualmente, um grande número de formadores (que provêm das escolas normais, das IREM, das M AFPEN) têm tomado dos saberes constituídos pela inovação didática ou institucional uma parte importante do que têm a transmitir. Portanto, interrogam-se os formadores do Ensino Elementar, que têm uma experiência já longa (vinte anos) de formação dos futuros professores, e sabe-se que lá também a experiência derrota as esperanças. 0 saber da inovação não resiste quase nada aos primeiros contatos com a classe: de volta dos estágios práticos, os jovens em formação inicial dizem freqüentementeter descoberto uma realidade de escola que não pode ser transmitida nem percebida até aquele momento pelos formadores. Essa heterogeneidade constatada pode lançar dúvida ou descrédito sobre a formação inteira. ${ }^{14}$

De fato, os professores, jovens ou confirmados, tentam inovar muito mais freqüentemente do que se acredita. Certamente, é

13. L'art et la science de l'enseignement, sob a direção de Marcel Crahay e Dominique Lafontaine, Liège, Labor, 1986, em particular: Michael Huberman, "Répertoires, recettes el vie de la classe: comment les enseignants utilisent l'information", pp. 151-183 e N. L. Gage, "Comment tirer un meilleur partie des recherches sur les processus d'enseignement?" pp. 411-434. Ver também: Christian Gambard, Recherche sur l'information el la culture dans le domaine de l'education concernant les enseignants dans les colléges, thése de doctorat, Université de Paris XIII, 1987; S, Alava, "Diffusion et utilisation de l'information éducative chez le instituteurs" Perspectives documentaires en éducation, 22, 1991.

14. VerTeacher's Lives and Careers, sob a dir. de S. Ball e I. Goodson, Lewes (U. K.), Palmer Press, 1982; Michael Huberman et al., La vie des enseignants. Paris Lausanne: Delachaux et Niestlé, 1988; Michael Huberman, "Les phases de la carrière enseignante". Revue française de pédagogie, 86, 1989, pp. 5-16. 
preci so distin guiren treastransforma ções, para algumas pessoas, de suas maneiras de fazereas transformações, mais raras, reconhecidas pelo espaço escolar, no confronto com o controle institucional, e eventualmente designadas como exemplares. Mas, aqui como lá, omite-se sempre que uma transformação bem-sucedida paga o preço de numerosas tentativas, abortadas, fracassadas ou abandonadas. Antes mesmo de toda inovação designada como tal, o ordinário da classe implica os tateamentos incessantes, as adaptações locais, as modificações provisórias sem as quais não se faz a classe. Entre a ino vação desejada ou autorizada pela instituição e as modificações singulares produzidas pelos atores do sistema; existe uma diferença de ponto de vista, não de natureza. De um lado, somente se retém aquilo que faz a diferença objetiva com relação a um estado presente do sistema; de outro, acumula-se o que de fato se diferencia na sua trajetória de formação na sua vida profissional: mas é somentenapráticaco tidianadaquelequecon duz a classe, que se podem formular e resolver os problemas engendrados pelas dinâmicas de evolução do ofício.

A oposição entre prática tradicional e prática inovadora, qualquer que seja o pólo valorizado, mascara de fato a existência de toda uma série de ações profissionais ordinárias que constituem o tronco sobre o qual vêm se enxertar os estilos pedagógicos ou didáticos específicos, tradicionais ou renovados. ${ }^{15}$ Ignorar os fazeres ordinários incapacita particularmente os professores no começo de carreira. E pode-se pensar que se não são resolvidas rapidamente as tensões nascidas deste desconhecimento, o professor arrisca a definir de maneira restritivasuasambiçõesprofissionais e se interdita das liberdades de ação que Ihe permitiriam fazer adaptações e inovar.

Como vimos, o fazer ordinário da classe não tem esta tu to no discur so detransmissão do saber profissional gestado na instituição escolar. Com efeito, é largamente ignorado pelas instituições de formação que, ao longo de toda sua história ${ }^{16}$, estão menos preocupadas em transmitir as táticas elementares que em anunciar a renovação das condutaspedagógicas ou didáticas. Deve ser abandonado ao ver fazer e ouvir dizer, às transmissões invisíveis que se fazem sobre o terreno nos contatos que se estabelecem entre professores tarimbados e professores iniciantes, na ocasião dos estágios práticos ou na vida cotidiana do estabelecimento escolar? Deve-se pensar que ele é, por natureza, dedicado a ser apagado, a ser identificado, num instan te, àin tu ição, que ele so men teéad qui ri do ao termo de um grande número de ensaios e erros, de fracassos freqüentemente graves e traumatizantes que constituíram um percurso inicial necessário na lenta apropriação do ofício? Essa é a parte definitivamente imersa do iceberg?

É preciso, portanto, encontrar os meios metodológicos de evidenciar os procedimentos ordinários da vida profissional, de construir o conjunto de gestos ignorados aos iniciantes, mas tornados invisíveis logo que aprendidos pelos mestres que adquiriram, ao fim de alguns anos, uma certa competência.

A aposta de uma tal pesquisa é dupla: legitimar o estudo dos procedimentos de trabalho, é tratar os professores como experts, mas também é se restringir a pensar o custo (em tempo, em segurança ou, possivelmente, em vigilância, em deboche ou economia de

15. Sobre a noção de estilo profissional, referimo-nos aos trabalhos de Erwin Goffman (ver, em particular, The presentation of self in everyday life, tr. fr.: La mise en scène de la vie quotidienne, tome 1, La presentation de soi, Paris, Ed. Minuit, 1973).

16. Não se dispõe ainda de uma boa história das práticas da formação de mestres na França. Fora as análises políticas de Maurice Gontard ( La Question des écoles normales primaires de la Révolution de 1789 à nos jours. Toulouse: CRDP/ Nathan, s.d. [1965]), e de Christian Nique (L'impossible gouvernement dês esprits. Histoire politique dês écoles normales primaires. Paris: Nathan, 1991) a tese de Gilles Laprévote (Splendeurs et misères de la formation des maitres. Les écoles normales primaires en France, 1879-1979. Lyon: PUL, 1984), único estudo deste tipo, fica muito evasiva sobre as práticas de formação e, em particular, sobre o papel das escolas de aplicação ou de lugares de estágio prático. 
energia etc.) desses procedimentos. Os saberes da prática seriam transmitidos no plano da nova formação profissional. Nessa perspectiva, tratar-se-ia de encontrar os dispositivos que pudessem tornar os saberes explícitos para as diversas categorias de formadores. É necessário, em particular, provocar um curto-circuito nas representações habituais que ignoram, na sua maioria, que a pedagogia é um trabalho. ${ }^{17}$ Ou, seja, dar aula é aproveitar uma intervenção pedagógica em termos de encargo de trabalho, de gasto de energia (custo das preparações, da organização, da gestão, do controle), em termos de negociação ou tática não dedutível de um projeto a priori ou de um programa. A urgência da ação aproxima as elaborações pro gramáticas à bricolagem e coloca violentamente em contraste as estratégias didáticas e as improvisações apressadas, o questionamento teórico dos discursos de formação e os imperativos pedagógicos do terreno.

Com efeito, o exercício do ofício do professor, qualquer que seja seu lugar de trabalho e seus constrangimentos específicos, se efetua no campo da classe, tendo em conta conjuntamente as exigências explícitas (as instruções oficiais, as modalidades escolares de organização e de avaliação, as demandas de sua hierarquia, o projeto que o professor formula a si mesmo) e as pressões implícitas como o ambiente sociocultural, as condições materiais (efetivos, arquitetura, orçamento da escola e alunos) ou ainda a atmosfera do estabelecimento (colegas, direção, pais de alunos etc.). ${ }^{18}$ Cada professor é, portanto, conduzido a negociar de maneira parcialmente dita, parcialmente sabida; e, sua maneira de fazer, a uma margem de jogo que autoriza uma diversidade regulada e limitada de práticas possíveis.

0 exercício do ofício docente se realiza também no tempo longo que autoriza as práticas múltiplas, mesmo contraditórias. As formas de organização e as técnicas de trabalho, os procedimentos de aprendizagem e as modalidades de avaliação, as intervenções educativas são tanto herdadas, imitadas e reproduzidas, quanto produzidas empiricamente, construídas e justificadas tecnicamente, ou teoricamente (em referência a um corpusconstituído de saberes), ou referidas a um conjunto de valores (uma concepção do bem-para-acriança, uma missão política da escola etc.). Conforme o caso, as práticas aparecem, portanto, como articulado rasdas escol has múl tiplas, hierarquizadas ou não, com tênue ou forte coerência, ecléticas ou sistemáticas, abertas ou fechadas, acabadas ou inacabadas, à fraca ou forte potencialidade da evolução.

Formula-se, portanto, que o campo da formação visa constituir o espaço da ação do cente, assim como a consciência clara do que define esse espaço e seu limite. Ora, não se pode confundir o espaço de ações potencialmente autorizadas institucionalmente e o espaço de ações praticamenteinvestidas por um docente dado. É bem este desvio que é preciso problematizar, no confronto entre ponto de vista institucional e dinâmicas pessoais.

Com efeito, o espaço de ação que cada docente se autoriza é definido exatamente pelos ges tos e pa la vrasque pode (queé suscetível de, capaz de, se acredita autorizado a) produzir no plano de sua função. Os critérios das escolhas pedagógicas são prioritariamente (mas não exclusivamente) referentesaoque cada um avalia empiricamente como satisfatório, isto é, dizer racionalmenterealizável no aqui e agora da classe. Se o processo de formação profissional não é senão um trabalho de progressiva descoberta (ou invenção) do registro infinito, mas não aleatório, dos gestos de trabalho racionalmente realizáveis,

17. Sobre a elaboração desta noção, que empresta suas proposições filosóficas de Hannah Arendt, ver Anne-Marie Chartier, "En quoi instruire est un métier?", Le Métier d'instruire, atas do colóquio de La Rochelle, sob a direção de Laurence Cornu, Poitiers, CRPD.

18. Os trabalhos de J ean-Louis Derouet e sua equipe (Grupo de estudos sociológicos do INRP) têm renovado as questões de maneira muito pertinente. Ver, por exemplo, o conjunto de artigos publicados na Recherche pédagogique, 95, 1991. 
então existem dois tempos distintos na vida profissional: o tempo ou a descoberta de bons gestos que tornam a vida cotidiana racionalmente realizável (quer dizer, viável), e é questão de urgência e de existênciaprofissional; e o tempo cujos critérios que presidem a reiteração, a modificação ou 0 abandono de gestos constituídos referem-se a um crescimento da satisfação.

0 primeiro tempo é maciçamente (mas não exclusivamente) dos iniciantes de carreira. 0 segun do co breaqueledaforma ção con tinuada dos docentes. É apenas lá que a inovação torna-se pensável e realizável como tal. É por isso que se deve velar particularmente pela maneira como se efetuam as apropriações inaugurais $^{19}$ dos primeiros gestos pedagógicos. É em referência a tais experiências que um docente é conduzido, seja a retificar a idéia de um espaço de ação mais circunscrito, seja a ampliar de maneira inacabável 0 espaço de ação que ele se autoriza e os registros das ações que ele julga possíveis.

Vê-se, a partir daí, as pesquisas se orientarem em duas direções que se sobrepõem apenas em parte, à medida que se privilegia no conjunto a reflexão sobre a inovação ou, ao contrário, os imperativos da formação.

A primeira direção do trabalho coloca que é possível e necessário repertoriar, por meio da disparidade indefinida dos gestos profissionais, as invariantes de intervenção pedagógica, ligadas não aos imperativos de toda transmissão dos saberes, mas à forma escolar de transmissão ${ }^{20}$ os invariantes, ou principalmente os traços de mais longa duração, constitutivos do nosso trabalho escolar, não prejulgando nem a evolução das disciplinas, nem as escolhas pedagógicas, nem as reformas institucionais, mas constituindo o solo referencial. A colocação em exercício, a colocação em representação dos traços de atividade sobre múltiplas formas (oposição rascunho/caderno por exem plo), a gestão da re i tera ção e do acontecimento etc., são assim formas de trabalho que não se deduzem de simples coações de aprendizagem. ${ }^{21}$ É difícil dizer a priori o que marca os constrangimentos ligados ao fechamento do espaço e do tempo (tempo curto da seqüência ou da jornada, tempo longo dos cursos escolares orientados); 0 que marca as pressões ligadas à obrigatoriedade ou à não-obrigatoriedade (para a escolamaternale o liceu), ao estatuto da infância, nas suas dimensões jurídicas de irresponsabilidade, mais também, políticas, psicológicas, econômicas, e que são características enfim de um certo modo de relação de saber, constitutivo dos valores escolares e das identidades docentes, como de suas evidências: por exemplo, a forma escolar do saber valorizado é sempre uma forma de linguagem (escrita, na maioria das vezes).

Essa direção de pesquisa define as intervenções na instituição escolar como as conceptualizações pedagógicas (quer sejam docentes, didáticas de especialidade, autores de manuais,formadores) cujo espaço de liberdade, portanto deinterven ção, énormatizado fortementepelasinvariantes. ${ }^{22}$ Toda possibilidade de inovação pedagógica exige, assim, que sejam elucidadas e trabalhadas as determinações fortes da ação. Inversamente, encontrar-se-á o que retoma com frescor renovado a análise sobre o começo de inovações pedagógicas que foram ou rejeitadas, digeridas e pervertidas pela instituição escolar, ou, ao contrário, integradas nas suas formas

19. Pierre Bourdieu. Le sens pratique, op. cit. pp. $90,102,113-114$.

20. Guy Vincent tem, inicialmente, acentuado sobre a pregnância da forma escolar e sobre algumas de suas características. Ver Guy Vincent, L'école primaire française. Étude sociologique. Lyon e Paris: Presses Universitaires de Lyon e Editions de la Maison des Sciences de l'homme, 1980.

21 L'exercise scolaire, sob a direção de J ean Hébrard, "Études de linguistique appliquée", 48, 1982. Ver também, com uma aproximação menos problematizada nesta perspectiva, "Travaux d'élèves. Pour une histoire des performances scolaires et de leur évaluation (1720-1830)", número especial de la Revue Histoire de l'Éducation, 46, 1990.

22. Ver o exemplo de invenção do exercício escolar de aplicação de texto em Anne-Marie Chartier e J ean Hébrard, Discours sur la lecture (1880-1980), op. cit., pp. 196-216. (Obra disponível em português.) 
variáveis, orgânicas ou marginais, institucionais ou militantes. ${ }^{23}$

Nessa perspectiva, uma formação inicial deveria trabalhar com os futuros professores, seja na escola ou nos colégios e liceus, essesesquemas de intervenção obrigatórios, uma vez que estão ligados aos constrangimentos estruturais do sistema atual. Parece, em particular, que o prolongamento da escolaridade obrigatória liga a escola ao colégio de maneira orgânica, produzindo efeitos ainda mal elucidados, modificando por exemplo os modos de relação com os saberes e a representação do saber, sem que, de outra forma, os outros constrangimentos (enclausuramento no tempo e espaço, grupo de crianças, polivalência do mestre etc.) sejam transformados. Seria, assim, importante ver em que medida a oposição historicamente fundamental entre primário e secundário é vá lida ainda hoje, ou se a oposição recente entre escola obrigatória e escola pós-obrigatória, que põe de um lado escola e colégio e de outro os liceus (geral, técni co ou pro fissi o nal) eosdiferentes tipos de Ensino Superior, ${ }^{24}$ não adquiriu uma pertinência tão forte. Um estudo sobre as práticas de trabalho nos colégios desde a reforma Haby poderá esclarecer esse ponto.

A segunda direção da pesquisa põe em primeiro plano os imperativos da formação ini cial. Partindo das pressões do conjunto de regras, sempre o racionalmente realizável no aqui e agora da classe, ela coloca que existem gestos profissionais de complexidade variável, dos quais uns são imediatamente disponíveis aos iniciantes e outros não, qualquer que seja 0 julgamento de valor que se deposita sobre os tais gestos. Em conseqüência, o colocar em dia as invariantes estruturais da forma escolar arrisca deixar um saber inutilizado se não mantém prioritariamente, nas múltiplas realizações que podem ser feitas, aquelasquepo dem consti tu irpon tos de apo io para osini ci an tesna vida profissional, elucidando os projetos limitados (mas provisoriamente limitados) que os autorizam, as táticas de administração do cotidiano que eles permitem, as variações que eles tornam possíveis. ${ }^{25}$

Tal complexidade é habitualmente hierarquizada conforme um sistema de tensões que associa ao simples o tradicional e ao complicado a renovação. Assim, a seqüência lição-exercícios, as formas magistrais de comunicação, o trabalho individual dos alunos etc., são considerados pelos iniciantes como tarefas fáceis de executar e, portanto, boas, mesmo que elas sejam apenas tarefas rotineiras de um mestre confirmado. Em oposição, a pedagogia do projeto, os contratos de trabaIho, a utilização de pequenos grupos, as técnicas sofisticadas de avaliação etc., parecem realçar a com plexidade enão po der ser executados a não ser pelos mestres confirmados, mesmo que essas tarefas sejam, apesar disso, as únicas que se pensem dignas de serem transmitidas.

Essas oposições são sem dúvidas cômodas, mas excessivamente simples. A complexidade do trabalho docente não pode ser posta em evidência e analisada a não ser mediante outros exames, sobre fenômenos freqüentemente considerados como triviais, por exemplo, consistiria em observar o uso do material pedagógico, em especial aquele que é fortemente estruturado (manuais escolares, fichas, repertórios de exercícios, fontes documentais elaboradas). Como fez uso dele um iniciante? E um mestre confirmado? Que economia de trabalho ele permitiu? Quais precauções foram-Ihe adicionadas nas diferentes etapas da carreira? Como se constituíram as regras de uso? Além das investigações pesadas, como

23. André Chervel, op. cit.

24 . Esta oposição introduzida pelos economistas da educação (ver, por exemplo, J oseph Debizet, "La scolarité après 16 ans", INSEE, "Donnés sociales" 1990, Paris, INSEE, 1990, pp. 330-335) tornou-se de uso corrente nas análises das políticas educativas.

25. Uma equipe do departamento "Politiques, pratiques et acteurs de l'education" do INRP propôs uma primeira aproximação dos problemas sem, no entanto, se instalar nas problemáticas que nós propusemos aqui. Ver: Instituteurs débutants: faciliter l'entrée dans le métier , sob a direção de Simone Baillauques e Andrée Louvet. Paris: AIRPE, 1991. 
esta que nós mencionamos, os estudos monográficos, o conjunto de entrevistas ou os registros de seqüências de classes constituem os dispositivosfacilmenteutilizáveis na formação. $\mathrm{Ou}$, ainda, os estudos dirigidos, nas classes existentes, sobre as decisões de vigilância dos indivíduos, e não mais de grupos, em que o do cente se impõe nas atividades ordinárias: vigilância à aprendizagem, aos fracassos e às suas modalidades, à duração relativa das tarefas etc. Em suma, ao orientar nossa pesquisa a partir de uma interrogação sobre os imperativos da formação inicial, somos levados a constituir não mais um repertório estrutural das invariantes da forma escolar, mas um meta- discurso que nos permita falar da escola na escola, para que se possa dizer, se fazer ver, se narrar, se deixar interrogar e pensar o trabalho ordinário dos docentes. Isso supõe um deslocamento de nossa atenção das observações aos dizíveis e, por conseqüência, às modalidades de se dizer (ou de se escrever). Se se consideram os constrangimentos práticosquepesam so breo fazer ordinário do ofício do formador, é necessariamente nesse sentido que nós seremos inicialmente conduzidos a trabalhar. 